\title{
Limit Support Pressure of Tunnel Face in Multi-Layer Soils Below River Considering Water Pressure
}

https://doi.org/10.1515/geo-2018-0074

Received December 20, 2017; accepted November 18, 2018

Abstract: This paper presents a method to determine the limit support pressure of tunnel face in multi-layer soils below river considering the water pressure. The proposed method is based on the 3D Terzaghi earth pressure theory and the wedge theory considering the water pressure. The limit support pressures are investigated using the limit equilibrium method and compared to those calculated using a numerical method, such as FLAC3D. Four cases focusing different combinations of three layers are analyzed. The results obtained by the numerical method agree well with the predictions of the proposed limit equilibrium method. The limit support pressure obtained using the limit equilibrium method is greater than that obtained by the numerical method. The limit equilibrium method is safe and conservative in obtaining the limit support pressure. The proposed limit equilibrium method is expected to be easily adaptable and to enhance the reliability of tunnel design and construction in multi-layer soils below river.

Keywords: Tunnel face; Limit support pressure; Multilayer soils; Limit equilibrium method; FLAC3D

\section{Introduction}

With a rapid increase in the construction of subways, shield tunnel technology has been widely used in the construction of tunnels [1-3]. Tunnel face stability is a key construction consideration in shield tunnel projects. Com-

\footnotetext{
*Corresponding Author: Weiping Liu: School of Civil Engineering and Architecture, Nanchang University, Nanchang 330031, China; Email:wpliu@126.com

Lina Hu, Yongxuan Yang: School of Civil Engineering and Architecture, Nanchang University, Nanchang 330031, China

Mingfu Fu: School of Civil Engineering and Architecture, Nanchang Institute of Technology, Nanchang 330099, China
}

plex geological conditions can pose serious technical challenges to shield tunnel excavation [4]. The support pressure counteracts the effective earth and water pressure. In order to ensure safety against the collapse of the tunnel face, it is essential to have a reliable analysis of tunnel face stability and predictions of the limit support pressure.

The limit support pressure of the tunnel face is the primary concern in stability analysis [5, 6]. The limit equilibrium method [7], numerical method [8, 9], and experimental method [10] are used to analyze the stability of the tunnel face and support pressure. For the experimental aspects on the stability of the tunnel face, Zhou et al. [11] used the in situ method to analyze the deformation that takes place close to the tunnel face. Messerli et al. [12] investigated the limit support pressure of the tunnel face in sand using experiments. Idinger et al. [13] used centrifuge model tests to investigate face stability on a small scale tunnel in cohesion-less soil, with the slip surface arising from a tunnel invert propagated at an angle of approximately $45^{\circ}+\varphi / 2$ to the horizontal. Chambon et al. [14] also studied tunnel face stability using a centrifuge test, and analyzed the effect of tunnel depths on the collapse forms of tunnel faces.

Numerical models are increasingly being used to assess the stability of tunnel faces. Zhang et al. [15] used a 2D numerical approach to study face stability during the slurry shield tunneling process. Chen et al. [16] constructed a 3D discrete element method to analyze the face stability of shallow shield tunnels in dry sand. Zhang et al. [17] adopted 3D numerical simulations to analyze the effects of diameter-to-depth ratios and soil properties on the tunnel face stability. Hasanpour et al. [18] simulated the single shield, double shield, and universal double shield for excavation of deep long tunnels. Graziani et al. [19] considered the creep effects for the Brenner Base Tunnel. Liu et al. [20] conducted a numerical analysis to investigate the influence of different construction schemes on the tunnel heave.

The wedge limit equilibrium model has become very popular in calculating the stability of the tunnel face [2124]. Lee et al. [25] revealed the influence of steel pipe- 
reinforced multi-step grouting on tunnel face stability using the limit equilibrium method. Xu et al. [26] calculated support pressure using the nonlinear Mohr-Coulomb failure criterion. Broere et al. [27] calculated the required limit support pressure using a time-dependent groundwater flow water model and the limit equilibrium wedge model. Leca et al. [28] assumed that the failure zone consisted of a series of conical bodies and derived the limit support pressure. Several researchers [29-31] derived the limit support pressure for tunnel face failure by assuming that the failure zone is a different shape. Zhang developed a horizontal slice method based on the limit equilibrium analysis theory to analyze tunnel face stability in soft surrounding rocks [32].

When the shield tunnel excavates below the river bed, high water pressure is encountered in the site [33]. Water pressure plays an important role in stability of tunnel excavation, and it may cause the stability of the tunnel face to become difficult to control [34]. If the applied face pressure is less than the limit support pressure, the tunnel face will collapse. The shield tunnel is inevitably constructed below the river, so the research on the stability of the tunnel face in multi-layer soils below river is significant. In this paper, the limit equilibrium method which takes water pressure into account is proposed for the calculation of the limit support pressure, and the solutions are compared with the numerical results for verification. The numerical analysis is carried out using FLAC3D [35].

\section{Methods}

The limit equilibrium method first proposed by Horn [36] is used to analyze the tunnel face stability. The tunnel face is supposed to be three-dimensional failure mode. The simple mechanism model of face stability is illustrated in Figure 1. The tunnel face mechanism approximates the circular face by means of a square and consists of a wedge and a right-angled prism. The wedge is assumed as a rigid body. $B, L, H$ are the width, length, and height of the prism, respectively. The soil is assumed to obey the Mohr-Coulomb failure condition with cohesion represented as $c$ and friction angle represented as $\varphi$.

The side length $B$ of the square is approximated by setting its area equal to that of the circular tunnel face $[36,37]$.

$$
B^{2}=\frac{1}{4} \pi D^{2}
$$

where $D$ is the tunnel diameter.

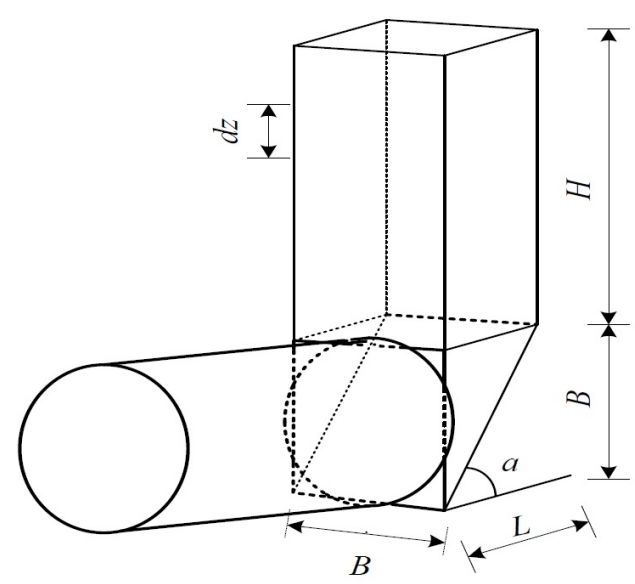

Figure 1: Wedge stability model

The inclination of wedge $\alpha$ is

$$
\alpha=45^{\circ}+\frac{\varphi}{2}
$$

The other side length of prism is

$$
L=\frac{B}{\tan \alpha}
$$

Consider an element having a dimension $d z$ within a prism of height $H$ as shown in Figure 1. The upper and lower vertical force of element are, respectively,

$$
P_{1}=A \sigma_{v}
$$

$$
P_{2}=A\left(\sigma_{v}+d \sigma_{v}\right)
$$

where $\sigma_{v}$ is the effective earth pressure from the overlying prism, $A$ is the cross-sectional area of prism.

The vertical friction applied to the lateral side of the element is

$$
f=k_{0} U \sigma_{v} \tan \varphi d z+U c d z
$$

where $U$ is the girth of prism, $k_{0}$ is coefficient of earth pressure at rest, and $k_{0}=1-\sin \varphi$.

The vertical equilibrium equation of $d z$ reads as follows

$$
k_{0} U \sigma_{v} \tan \varphi d z+U c d z+A\left(\sigma_{v}+d \sigma_{v}\right)-A \sigma_{v}=\gamma A d z
$$

where $\gamma$ is the gravity of the soil.

From the equilibrium equation of the forces acting on the wedge Eq. (7), with boundary conditions $z=0, \sigma_{v}=$ $p_{0}, p_{0}$ is the surcharge on the surface. The effective earth pressure acting upon the wedge can be calculated using the following equation.

$$
\sigma_{v}=\frac{A \gamma-U c}{U k_{0} \tan \varphi}\left(1-e^{\frac{-z U k_{0} \tan \varphi}{A}}\right)+p_{0} e^{\frac{-z U k_{0} \tan \varphi}{A}}
$$


In practical engineering, the overburden layer of a tunnel is often the composite layers. In this paper, the effect of a multi-layered overburden on the overlying earth pressure also can be taken into account. A model of earth pressure calculation is shown in Figure 2.

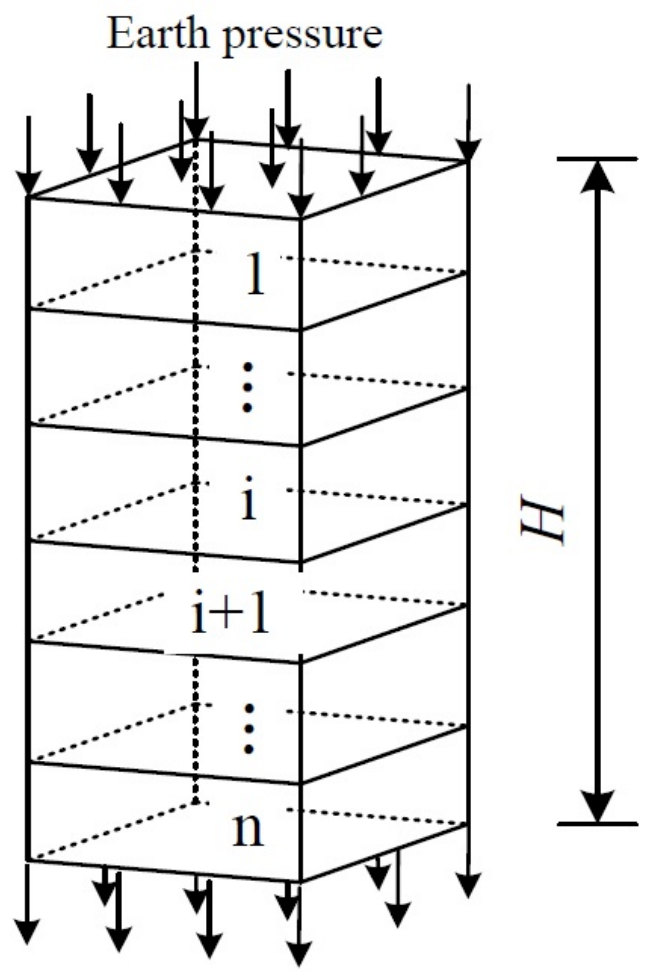

Figure 2: Model of earth pressure calculation

It is assumed that there are $n$ layers in the composite soils. $\sigma_{v 1}$ and $\sigma_{v i}$ are the earth pressures acting upon the wedge of the first and $i$-th layer, respectively. They can be respectively expressed as

$$
\begin{gathered}
\sigma_{v 1}=\frac{A \gamma_{1}-U c_{1}}{U k_{01} \tan \varphi_{1}}\left(1-e^{\frac{-z_{1} U k_{01} \tan \varphi_{1}}{A}}\right)+p_{0} e^{\frac{-z_{1} U k_{01} \tan \varphi_{1}}{A}} \\
\sigma_{v i}=\frac{A \gamma_{i}-U c_{i}}{U k_{0 i} \tan \varphi_{i}}\left(1-e^{\frac{-z_{i} U k_{0 i} \tan \varphi_{i}}{A}}\right)+\sigma_{v i-1} e^{\frac{-z_{i} U k_{0 i} \tan \varphi_{i}}{A}}
\end{gathered}
$$

The earth pressure of the No. $n$ layer can be obtained using a layer to layer method.

$$
\begin{aligned}
& \sigma_{v n}=\sum_{i=2}^{n} \frac{A \gamma_{i}-U c_{i}}{U k_{0 i} \tan \varphi_{i}}\left(1-e^{\frac{-z_{i} U k_{0 i} \tan \varphi_{i}}{A}}\right) \\
& \prod_{i=1}^{i-1} e^{\frac{-z_{i} U k_{0 i} \tan \varphi_{i}}{A}}+\frac{A \gamma_{n}-U c_{n}}{U k_{0 n} \tan \varphi_{n}}\left(1-e^{\frac{-z_{n} U k_{0 n} \tan \varphi_{n}}{A}}\right)
\end{aligned}
$$

$$
+p_{0} \prod_{i=1}^{n} e^{\frac{-z_{i} U k_{0 i} \tan \varphi_{i}}{A}}
$$

Wedge analysis based on the limit equilibrium theory is adopted to obtain the support pressure for the tunnel face stability. Assuming the failure criterion holds along the failure face, a static equilibrium equation can be set up. When a shield tunnel is located below the river, the stability analyses of the shield tunnels face needs to consider the influence of water pressure. Water pressure is usually considered an external force [33], and the forces acting upon the wedge at the face are illustrated in Figure 3. A hydrostatic distribution of water pressures along the slip surface is assumed. There is an effective earth stress $\sigma_{v}$ at the wedge-prism-interface, the self-weight of wedge $G$, the support force $P$ at the tunnel face, the normal force Non the inclined sliding surface, the shear forces $T$ on the inclined as well as on the sliding surface, the symmetric normal force $N^{\prime}$ and the shear force $T^{\prime}$ on the two lateral surfaces of the wedge.

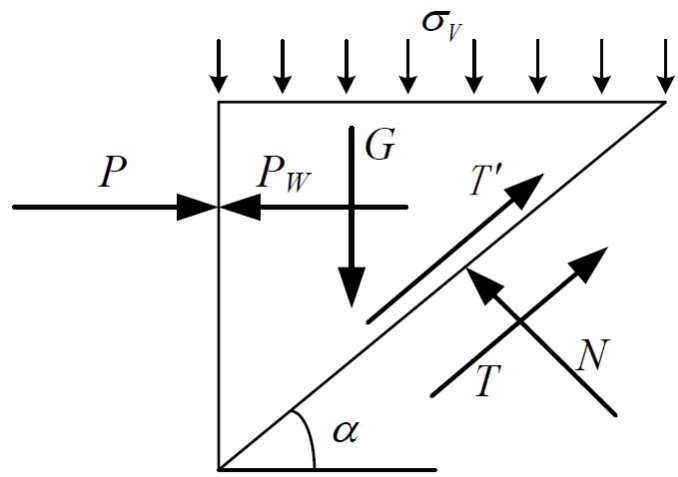

Figure 3: Forces acting upon the wedge

The self-weight of the wedge $G$

$$
G=\frac{\gamma B^{3}}{2 \tan \alpha}
$$

where $B$ is the height of the wedge.

The vertical mean stress $\sigma_{z}^{\prime}$ on the inclined sliding surface

$$
\sigma_{z}^{\prime}=\frac{2 \sigma_{v n}}{3}+\frac{B \gamma}{3}
$$

The shear forces $T$ on the inclined sliding surface

$$
T=\frac{c B^{2}}{\sin \alpha}+N \tan \varphi
$$

The shear force $T^{\prime}$ on the two sides of the wedge

$$
T^{\prime}=\frac{B^{2}}{2 \tan \alpha}\left(c+k_{0} \sigma_{z}^{\prime} \tan \varphi\right)
$$


The vertical earth pressure $P_{v}$ acting on the top of wedge is presented as

$$
P_{v}=A \sigma_{v}=B L \sigma_{v}
$$

When not taking the infiltration in the excavation face into account, the overburden strata are assumed to be permeable with high permeability, such as sand. Thus, a complete hydraulic connection exists between the river water and the groundwater [38]. The water table can be assumed to be at the surface of the river water for the computation of water pressure acting on the tunnel. In this sense, the water pressure generated by river water can be expressed as

$$
P_{w}=B^{2}\left(\sum \gamma_{w} z_{i}+\gamma_{w} h\right)
$$

where $\gamma_{w}$ is the unit weight of water, $z_{i}$ is the thickness of the $i$-th stratum, which is located above the center point of the tunnel face.

According to the limit equilibrium principles, force equilibrium is realized horizontally and vertically. By considering the water pressure and equating force in the vertical and horizontal directions, the equations of equilibrium in the horizontal and vertical dimensions are obtained as

$$
\begin{aligned}
& P-P_{w}+T \cos \alpha+2 T^{\prime} \cos \alpha=N \sin \alpha \\
& P_{V}+G=T \sin \alpha+2 T^{\prime} \sin \alpha+N \cos \alpha
\end{aligned}
$$

By solving the equilibrium Equations (18) and (19), the limit support force on the tunnel face is calculated as

$$
P=\varepsilon\left(\sigma_{v} B L+G\right)-\left(\frac{c B^{2}}{\sin \alpha}+2 T^{\prime}\right)(\varepsilon \sin \alpha+\cos \alpha)+P_{w}
$$

where $\varepsilon=\frac{\sin \alpha-\tan \varphi \cos \alpha}{\cos \alpha+\tan \varphi \sin \alpha}$.

The face stability analysis relevant to a circular rigid tunnel could be idealized. The support pressure is simplified to be uniform [17]. The minimal support pressure termed as the limit support pressure $\sigma_{T}$ can be calculated with consideration of water pressure in river and is given as

$$
\sigma_{T}=\frac{P}{B^{2}}
$$

\section{Results}

\subsection{Results using the numerical method}

The validity of the proposed method is evaluated in this section through a comparison with the numerical model using FLAC3D. The FLAC3D is adopted to predict the limit state and the development of deformation. An explicit Lagrangian calculation scheme is used in the FLAC3D. This is a forward scheme for a nonlinear problem which does not require iteration [18]. This code can deal with the large deformation problem very well and can avoid the problem of numerical instabilities during analysis [39-41]. Therefore, the FLAC3D is adopted to simulate the limit support pressure. The FLAC3D model is shown in Figure 4. The threedimensional numerical model is $40 \mathrm{~m}$ long, $21 \mathrm{~m}$ wide, and $30 \mathrm{~m}$ high. A circular tunnel under the three layers soils is considered in evaluating the limit support pressure on the tunnel face. The tunnel support parameters are as follows: the segment is $\mathrm{C} 50$ concrete, the segment thickness is $30 \mathrm{~cm}$, the Young modulus of the concrete segment is $34.5 \mathrm{GPa}$, Poisson' ratio of the concrete segment is 0.2 , and the density is $2.45 \mathrm{~g} / \mathrm{cm}^{3}$. The parameters of the tunnel and soils are selected from the case of subway Line No.1 across the Ganjiang River. A circular tunnel with a diameter $D$ of $6 \mathrm{~m}$, a tunnel depth $H$ of $12 \mathrm{~m}$, and a water depth $h$ of $10 \mathrm{~m}$ in river is assumed. The analysis is conducted using a linear Mohr-Coulomb yield criterion. Analyses are performed for the four cases, and the mechanical parameters of friction angle $\varphi$ and cohesion $c$ of the soil stratum are summarized in Table 1. The four cases are used to analyze the situations with the excavation layer as cohesive soil or cohesive soil, and the cases of overlying soil as cohesive soil or cohesive soil. The soil thicknesses of 1-1, 1-2, 1-3 are $6 \mathrm{~m}$, 6 m, 18 m, respectively. For stratum 1-1, 1-2, 1-3, an elastic modulus $E$ o f $40 \mathrm{MPa}$, Poisson' ratio $v$ of 0.33 , and gravity $\gamma$ of $20 \mathrm{kN} / \mathrm{m}^{3}$ of are selected.

Table 1: Mechanical parameters of soil

\begin{tabular}{lllllllll}
\hline \multirow{2}{*}{ soil } & \multicolumn{2}{l}{ Case $\mathrm{A}$} & \multicolumn{2}{c}{ Case B } & \multicolumn{2}{c}{ Case C } & \multicolumn{2}{c}{ Case D } \\
\cline { 2 - 8 } & $c / \mathrm{kPa} \varphi /{ }^{\circ}$ & $c / \mathrm{kPa}$ & $\varphi /{ }^{\circ}$ & $c / \mathrm{kPa}$ & $\varphi /{ }^{\circ}$ & $c / \mathrm{kPa} \varphi / /^{\circ}$ \\
\hline $1-1$ & 0 & 25 & 5 & 35 & 0 & 25 & 5 & $35 \mathrm{~S}$ \\
$1-2$ & 5 & 35 & 0 & 25 & 5 & 35 & 0 & 25 \\
$1-3$ & 0 & 25 & 0 & 25 & 5 & 35 & 5 & 35 \\
\hline
\end{tabular}

The analyses of tunnel face stability and supporting pressure are performed with FLAC3D. The applied support pressure can be normalized by the initial earth pressure [42]. The support pressure ratiois equal to the applied support pressure divided by the initial horizontal earth stress at the center of the tunnel face. The initial support pressure on the face is set as the initial horizontal earth pressure, and is gradually reduced until the tunnel face collapses. The displacements in the surrounding ground have been highlighted. Displacement contours 


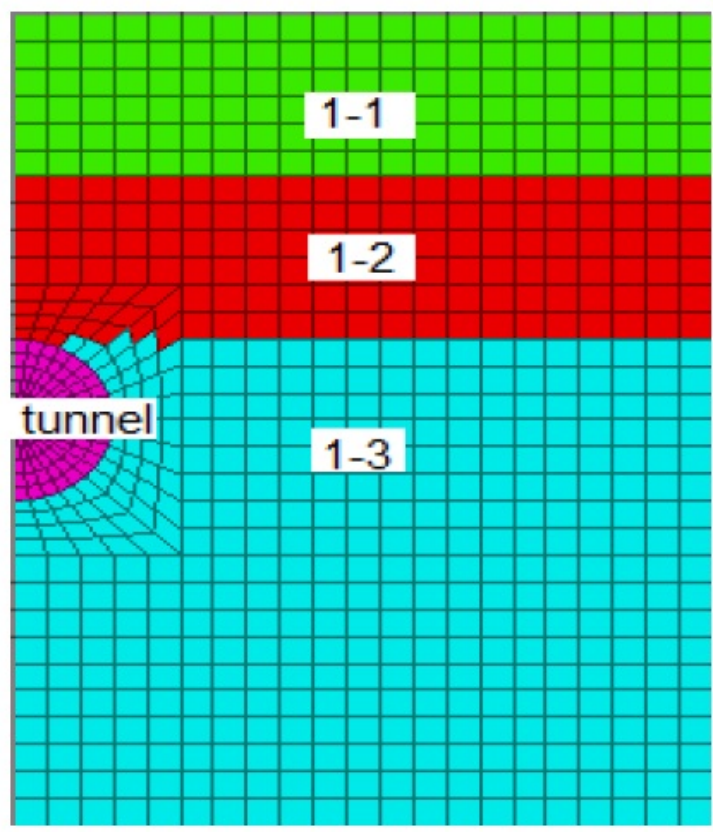

Figure 4: Numerical model of calculation

around tunnel face and the displacement fields for case A, case B, case $\mathrm{C}$, and case D are plotted in Figure 5. The monitoring displacements in Figure 5 are in the horizontal direction (excavation direction), and the unit of the displacement is in meters. The displacements of the tunnel face are calculated according to the different cases with a variation in soil layers. For case A and case B, the tunnel faces are in cohesionless soils. Case $\mathrm{C}$ and case $\mathrm{D}$ are in cohesivefrictional soils.

The failure zones in case A and case B are obviously larger than that in case $\mathrm{C}$ and case $\mathrm{D}$, and mainly concentrate in the upper region of tunnel face. By comparing Figure 5(a) and Figure 5(b), it is evident that the case A has the larger zone of sliding, but is blocked by the cohesive soil layer 1-2 and is mainly concentrate in the soil layer 1-3. The sliding zone in case B extends gradually to the river bed surface, the displacement decreases drastically. For case $C$ and case $\mathrm{D}$, when the tunnel excavates in the cohesive soil layer, the sliding zone shrinks and concentrates in front of the tunnel face. It is obvious that cohesion has an important influence on the failure form.

Tunnel face stability and the behavior of surrounding soils are analyzed with varying support pressure ratios at the tunnel face. Evaluating the relationship between the displacement of a control point (the face center) and the applied support pressure ratio (normalized by initial stress) is a common way to analyze the tunnel face stability [43]. Figure 6(a) and Figure 6(b) show horizontal and vertical displacement of the face center with a variation of support pressure ratios for the case A, case $\mathrm{B}$, case $\mathrm{C}$, and case $\mathrm{D}$, respectively. Large displacement is expected to occur when there is small support pressure ratio. The displacement increases significantly when the support pressure ratio decreases to a certain value. This value is the limit support pressure ratio. From the results of the FLAC3D analysis for the four cases previously mentioned, the calculation results of the limit support pressure on the tunnel face are shown in Table 2.

Table 2: Results with the FLAC3D

\begin{tabular}{llll}
\hline Case & $\begin{array}{l}\text { Initial earth } \\
\text { pressure } / \mathrm{kPa}\end{array}$ & $\begin{array}{l}\text { Limit support } \\
\text { pressure ratio }\end{array}$ & $\begin{array}{l}\text { Limit support } \\
\text { pressure } / \mathrm{kPa}\end{array}$ \\
\hline A & 275 & 0.755 & 207.63 \\
B & 275 & 0.78 & 214.50 \\
C & 275 & 0.715 & 196.63 \\
D & 275 & 0.720 & 198.00 \\
\hline
\end{tabular}

\subsection{Results using the limit equilibrium method}

Comparative calculations are carried out. The same cases are analyzed using the proposed limit equilibrium method and numerical method using FLAC3D. The analyses of the tunnel face supporting pressure with the proposed limit equilibrium method are preformed. Table 3 compares the limit support pressure obtained using the limit equilibrium method with that obtained from the numerical method.

Table 3: Results of limit support pressure

\begin{tabular}{lllll}
\hline & A & B & C & D \\
\hline numerical method & 207.63 & 214.50 & 196.63 & 198.00 \\
limit equilibrium method & 219.01 & 229.27 & 197.72 & 204.39 \\
error & $5.19 \%$ & $6.44 \%$ & $0.55 \%$ & $3.12 \%$ \\
\hline
\end{tabular}

\section{Discussion}

The results of case A and case $\mathrm{B}$, which were excavated in cohesionless soil, are different. The error of them is nearly $10 \%$, although the tunnel excavates at the same soil layer. The reason is that the upper soil layer 1-2 in case A is comprised of cohesive soils, which are conducive to the stability of the tunnel face and prevent the development of a fail- 
Contour Of Displacement $/ \mathrm{m}$

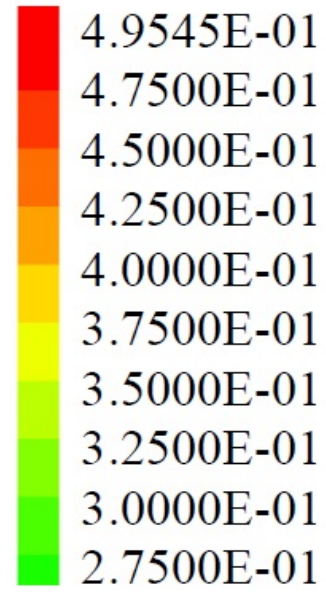

(a) Case A

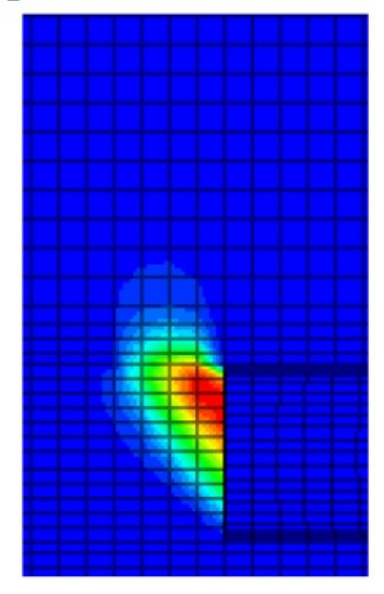

Contour Of Displacement $/ \mathrm{m}$

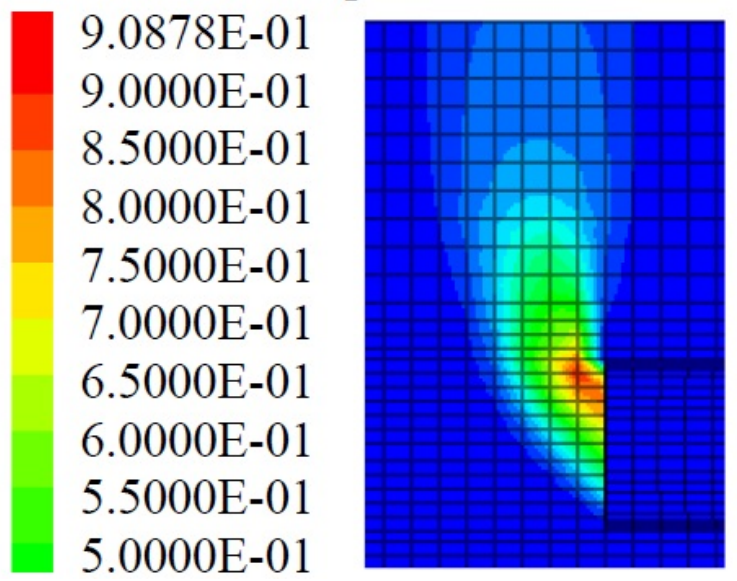

(b) Case B

\section{Contour Of Displacement $/ \mathrm{m}$}

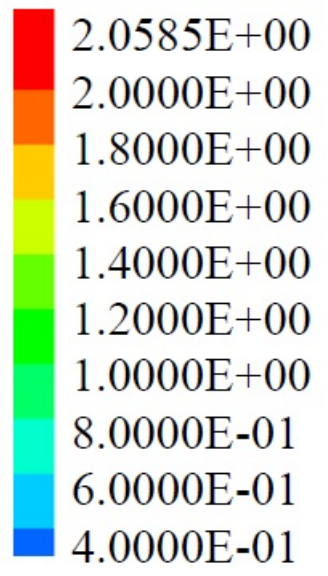

(c) Case $\mathrm{C}$

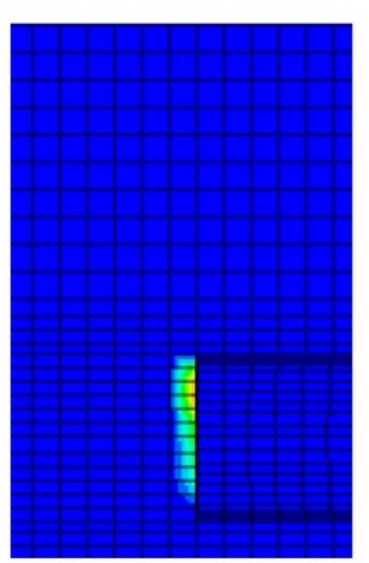

(d) Case D

\section{Contour Of Displacement $/ \mathrm{m}$}

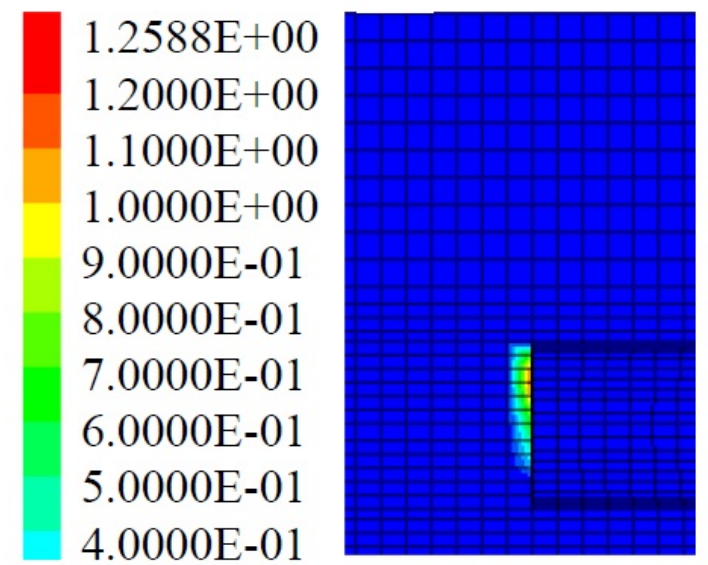

Figure 5: Displacement contours around the tunnel face

ure zone. Thus, the required limit support pressure to keep the tunnel face stable in case A is small compared to that in case B. When the excavation is in the cohesive soil for case $\mathrm{C}$ and case $\mathrm{D}$, their required limit support pressures are similar, although the cover soil layers are different. The limit support pressure in case A and case B are obviously greater than that in case $C$ and case $D$. The main reason is that the excavation stratum of case A and case B is cohesionless soil.

The limit support pressures calculated by limit equilibrium method are $219.01 \mathrm{kPa}, 229.27 \mathrm{kPa}, 197.72 \mathrm{kPa}$, $204.39 \mathrm{kPa}$ for the cases A, B, C, and D, respectively. The results of the limit equilibrium method agree well with numerical calculations with respect to the limit support pressure, as shown in Table 3. The obtained results suggest that the approach proposed herein could be applied for fast estimations of the pressure needed for face support in multilayer soils below river, with consideration to water pressure. These values are about $5 \%$ higher than the prediction from the numerical method. Mollon et al. [44] got a similar result for a 2D stability analysis of a pressurized tunnel face in sand. The proposed limit equilibrium method is also an effective method to calculate the limit support pressure on the tunnel face for permeable overburden strata that has a high permeability. It cannot be used for impermeable overburden strata that has a low permeability. The proposed method is suitable for cohesionless soil. The proposed method is reliable and effective when it is used to design the tunnel excavation process. 


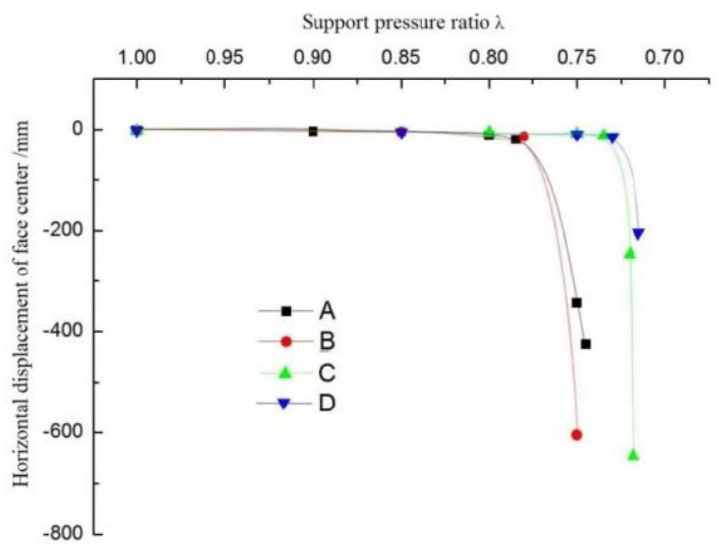

(a) Horizontal displacement

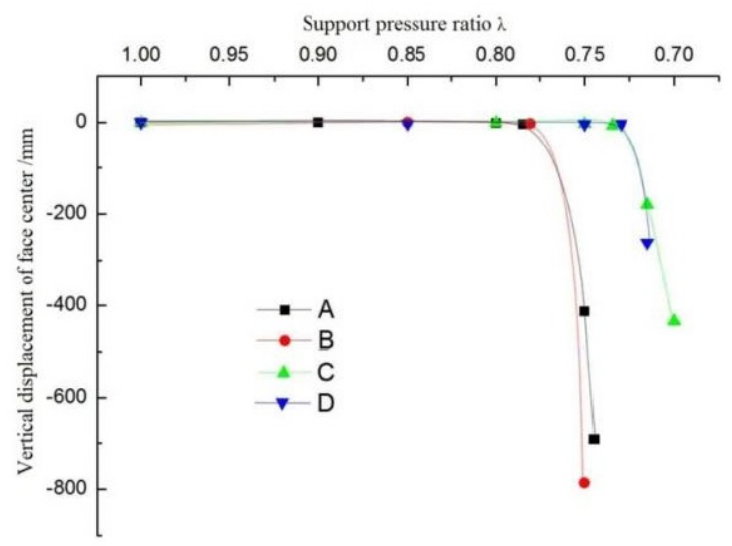

(b) Vertical displacement

Figure 6: Displacement of the central point of face

\section{Conclusions}

Managing suitable support pressures acting on a tunnel face is very important in stabilizing the tunnel face. In this paper, a limit equilibrium method with considerations for water pressure is proposed to determine the limit support pressure of tunnel faces in multi-layer soils below river. Based on the proposed limit equilibrium methods, the limit support pressures required for tunnel face stability below the river bed are estimated on variable ground. The face stability is also investigated using the FLAC3D. The limit support pressures have been calculated to compare the results of the limit equilibrium method with those from a three-dimension numerical method FLAC3D. There is good agreement between the limit equilibrium results and the numerical results. The limit support pressure using the limit equilibrium method is greater than that obtained by the numerical method. It is safe and efficient when the limit equilibrium method is used to design the support pressure on tunnel face with permeable overburden strata that has a high permeability. This research can provide a theoretical foundation for tunnel engineering practices in multi-layer soils below the river bed. The next stage of the work is studying the limit support pressure for impermeable overburden strata that has a low permeability.

Acknowledgement: The authors gratefully acknowledge the financial support from the National Natural Sciences Foundation of China (Grant: 51468041) and Jiangxi Science Foundation (Grant: 20124ABE02106, 20161BAB203078).

\section{References}

[1] Lin C.G., Zhang, Z.M., Wu, S.M., Yu, F., Key techniques and important issues for slurry shield under-passing embankments: a case study of Hangzhou Qiantang River Tunnel. Tunnelling and Underground Space Technology, 2013, 38, 306-325

[2] Tóth á., Gong Q.M., Zhao J., Case studies of TBM tunneling performance in rock-soil interface mixed ground. Tunnelling and Underground Space Technology, 2013, 38, 140-150

[3] Kavvadas M.J., Monitoring ground deformation in tunnelling: current practice in transportation tunnels. Engineering Geology, 2005, 79, 93-113

[4] Zhou H., Gao Y., Zhang C.Q., Yang F.J., Hu M.M., Liu H.T., Jiang Y., A 3D model of coupled hydro-mechanical simulation of double shield TBM excavation. Tunnelling and Underground Space Technology, 2018, 71, 1-4

[5] Klar A., Osman A. S., Bolton M., 2D and 3D upper bound solutions for tunnel excavation using 'elastic' flow fields. International Journal Numerical Analytical Method in Geomechanics, 2007, 31, 1367-1374

[6] Zhao K., Janutolo M., Barla G., A completely 3D model for the simulation of mechanized tunnel excavation. Rock Mechanics and Rock Engineering, 2012, 45, 475-497

[7] Mollon G., Phoon K.K., Dias D., Soubra A.H., A new 2D failure mechanism for face stability analysis of a pressurized tunnel in spatially variable sands. GeoFlorida 2010: Advances in Analysis, Modeling \& Design, Florida, 2010, 2052-2061

[8] Ebadati N., Kaboli M., Modeling stress distribution and the change of ground behavior during excavation of Tehran city underground tunnel, Journal of Geotechnical Geology, 2014, 9, 293-304

[9] Haghi A.H., Asef M.R., Taheri A., Mohkam M., Evaluation of the Heading Confinement Pressure Effect on Ground Settlement for EPBTBM Using Full 3D Numerical Analysis, International Journal of Mining \& Geo-Engineering, 2013, 47, 13-32

[10] Takano D., Otani J., Nagatani H., Mukunoki T., Application of Xray $\mathrm{CT}$ boundary value problems in geotechnical engineeringResearch on tunnel face failure, Proc. Geocongress, ASCE, Reston, Va, 2006, 1-6

[11] Zhou H., Qu C.K., Hu D.W., Zhang C. Azhar M.U., Shen Z., Chen J., In situ monitoring of tunnel deformation evolutions from auxiliary tunnel in deep mine. Engineering Geology, 2017, 221, 10-15 
[12] Messerli J., Pimentel E., Anagnostou G., Experimental study into tunnel face collapse in sand, ,.Proceedings of the 7th International Conference on Physical Modelling in Geotechnics, Zurich, Switzerland, 2010, 575-580

[13] Idinger G., Aklik P., Wu W. Borja R.I., Centrifuge model test on the face stability of shallow tunnel. Acta Geotechnica, 2011, 6, 105-117

[14] Chambon P., Corté J.F., Shallow tunnels in cohesionless soil stability of tunnel face. Journal of Geotechnical Engineering, 1994, $120,1148-1165$

[15] Zhang Z.X., Hu X.Y., Scott K.D., A discrete numerical approach for modeling face stability in slurry shield tunnelling in soft soils. Computers and Geotechnics. 2011, 38, 94-104

[16] Chen R.P., Tang L.J., Ling D.S., Chen Y.M., Face stability analysis of shallow shield tunnels in dry sandy ground using the discrete element method. Computers and Geotechnics, 2011, 38, 187-195

[17] Zhang C.P., Han K.H., Zhang D.L., Face stability analysis of shallow circular tunnels in cohesive-frictional soils. Tunnelling and Underground Space Technology, 2015, 50, 345-357

[18] Hasanpour R., Advance numerical simulation of tunneling by using a double shield TBM. Computers and Geotechnics, 2014, 57, 37-52

[19] Graziani A., Capata A., Romualdi P., Analysis of rock-TBM-lining interaction in squeezing rock. Felsbau Magazin, 2007, 25, 23-31

[20] Liu H.L., Li P., Liu J.Y., Numerical investigation of underlying tunnel heave during a new tunnel construction. Tunnelling and Underground Space Technology, 2011, 26, 276-283

[21] Anagnostou G., Kovári K., Face stability conditions with earth pressure balanced shields. Tunnelling and Underground Space Technology, 1996, 11, 165-173

[22] Broere W., On the face support of microtunnelling TBMs. Tunnelling and Underground Space Technology, 2015, 46, 12-17

[23] Khezri N., Mohamad H., Fatahi B., Stability assessment of tunnel face in a layered soil using upper bound theorem of limit analysis. Geomechanics and Engineering, 2016, 11, 471-492

[24] Anagnostou G., Kovári K., The face stability of slurry-shield driven tunnels. Tunnelling and Underground Space Technology, 1994, 9, 165-174

[25] Lee I.M., Lee J.S., Nam S.W., Effect of seepage force on tunnel face stability reinforced with multi-step pipe grouting. Tunnelling and Underground Space Technology, 2004, 19, 551-565

[26] Xu J.S., Du D.C., Yang Z.H., Upper bound analysis for deep tunnel face with joined failure mechanism of translation and rotation, Journal of Central South University, 2015, 22, 4310-4317

[27] Broere W., van Tol A.F., Time-dependant infiltration and groundwater flow in a face stability analysis. Proceeding of the International Symposium Kyoto 2001: Modern Tunneling Science and Technology, Kyoto, Japan, 2001, 629-634

[28] Leca E., Dormieux L., Upper and lower bound solutions for the face stability of shallow circular tunnels in frictional material. Géotechnique, 1990, 40, 581-606
[29] Krause, T., Schildvortrieb mit flüssigkeits-und erdgestützter ortsbrust. PhD Thesis, Technical University Carolo-Wilhelmina, 1987

[30] Soubra A.H., Kinematical approach to the face stability analysis of shallow circular tunnels. In: Proc. 8th International Symposium of Plasticity., Canada, British Columbia,2002, 443-445

[31] Mollon G., Dias D., Soubra A.H., Rotational failure mechanisms for the face stability analysis of tunnels driven by pressurized shields. International Journal Numerical Analytical Method in Geomechanics, 2011, 35, 1363-1388

[32] Zhang Z.Q., Shi X.Q., Wang B., Li H.Y., Stability of NATM tunnel faces in soft surrounding rocks. Computers and Geotechnics, 2018, 96, 90-102

[33] Min F.L., Zhu W., Lin C., Guo X.J., Opening the excavation chamber of the large-diameter size slurry shield: A case study in Nanjing Yangtze River Tunnel in China. Tunnelling and Underground Space Technology, 2015, 46, 18-27

[34] Qiu Y., Yang X.A., Xu Q.W., Guo L., Tang Z. H., Li Z., Analysis on stability and instability risk of excavation face of shield tunnel in water-rich sand layer. China Railway Science, 2015, 36, 55-62.

[35] Itasca Consulting Group Inc, FLAC3D Manual, third ed. (FLAC3D Version 3.1), 2006

[36] Horn N., Horizontaler erddruck auf senkrechte abschlussflächen von tunnelröhren, Landeskonferenz der ungarischen tiefbauindustrie, 1961, 7-16

[37] Bai Y.X., Qi T.Y., Ren G.Q., Xie J.Q., Research on calculation model of limit support pressure on shield face in sandy cobble stratum. Journal of the China Railway Society, 2013, 35(7), 114122

[38] Lin C.G., Wu S.M., Xia T.D., Design of shield tunnel lining taking fluctuations of river stage into account. Tunnelling and Underground Space Technology, 2015,45, 107-127

[39] Mollon G., Dias D., Soubra A.H., Probabilistic Analysis of Circular Tunnels in Homogeneous Soil Using Response Surface Methodology. Journal of Geotechnical and Geoenvironmental Engineering, 2009, 135, 1314-1325

[40] Lin P., Zhou Y.N., Liu H.Y., Wang C., Reinforcement design and stability analysis for large-span tailrace bifurcated tunnels with irregular geometry. Tunnelling and Underground Space Technology, 2013, 38, 189-204

[41] Diederichs M. S., Mechanistic interpretation and practical application of damage and spalling prediction criteria for deep tunnelling. Canadian Geotechnical Journal, 2007, 44, 1082-1116

[42] Huang Z.R., Zhu W., Liang J.H., Qin J.S., A study on the limit support pressure at excavation face of shield tunneling. China Civil Engineering Journal, 2006, 39,112-116.(in Chinese with English abstract)

[43] Vermeer P.A., Ruse N., Marcher T., Tunnel heading stability in drained ground. Felsbau, 2002, 20, 8-18

[44] Mollon G., Phoon K.K., Dias D., Soubra A.H., Validation of a New 2D Failure Mechanism for the Stability Analysis of a Pressurized Tunnel Face in a Spatially Varying Sand. Journal of Engineering Mechanics, 2011, 137, 8-21 